\title{
DNA hypermethylation and decreased mRNA expression of MAL, PRIMA1, PTGDR and SFRP1 in colorectal adenoma and cancer
}

Alexandra Kalmár ${ }^{1,2^{*}+}$, Bálint Péterfia ${ }^{1,2 \dagger}$, Péter Hollósi ${ }^{3,4 \dagger}$, Orsolya Galamb², Sándor Spisák², Barnabás Wichmann², András Bodor ${ }^{5}$, Kinga Tóth ${ }^{1}$, Árpád V. Patai ${ }^{1}$, Gábor Valcz², Zsófia Brigitta Nagy', Vivien Kubák ${ }^{3}$, Zsolt Tulassay ${ }^{1,2}$, llona Kovalszky ${ }^{3}$ and Béla Molnár ${ }^{1,2}$

\begin{abstract}
Background: Colorectal cancer (CRC) development is accompanied by changes in expression for several genes; but the details of the underlying regulatory procesess remain unknown. Our aims were to assess the role of epigenetic processes in tumour formation and to identify characteristic DNA methylation and miRNA alterations in the colorectal adenoma-carcinoma sequence.

Methods: Whole genome expression profiling was performed on colonic biopsy samples (49 healthy normal, 49 colorectal adenoma (AD), 49 CRC); on laser capture microdissected (LCM) epithelial and stromal cells from 6 CRC-normal adjacent tissue (NAT) samples pairs, and on demethylated human CRC cell lines using HGU133 Plus 2.0 microarrays (Affymetrix). Methylation status of genes with gradually altering expression along the AD-CRC sequence was further analysed on 10-10 macrodissected and 5-5 LCM samples from healthy colon, from adenoma and from CRC biopsy samples using bisulfite-sequencing PCR (BS-PCR) followed by pyrosequencing. In silico miRNA prediction for the selected genes was performed with miRWALK algorithm, miRNA expression was analysed on 3 CRC-NAT sample pairs and 3 adenoma tissue samples using the Human Panel I + II (Exiqon). SFRP1 immunohistochemistry experiments were performed.

Results: A set of transcripts (18 genes including MAL, SFRP1, SULT1A1, PRIMA1, PTGDR) showed decreasing expression $(p<0.01)$ in the biopsy samples along the adenoma-carcinoma sequence. Three of those (COL1A2, SFRP2, SOCS3) showed hypermethylation and THBS2 showed hypomethylation both in AD and in CRC samples compared to NAT, while BCL2, PRIMA1 and PTGDR showed hypermethylation only in the CRC group. miR-21 was found to be significantly $(p<0.01)$ upregulated in adenoma and tumour samples compared to the healthy colonic tissue controls and could explain the altered expression of genes for which DNA methylation changes do not appear to play role (e.g. BCL2, MAL, PTGS2). Demethylation treatment could upregulate gene expression of genes that were found to be hypermethylated in human CRC tissue samples. Decreasing protein levels of SFRP1 was also observed along the adenoma-carcinoma sequence.

Conclusion: Hypermethylation of the selected markers (MAL, PRIMA1, PTGDR and SFRP1) can result in reduced gene expression and may contribute to the formation of colorectal cancer.
\end{abstract}

Keywords: DNA methylation, Colorectal cancer, Gene expression, Pyrosequencing, Laser capture microdissection

\footnotetext{
* Correspondence: alexandra.kalmar@gmail.com

tEqual contributors

'2nd Department of Internal Medicine, Semmelweis University, Budapest,

Hungary

${ }^{2}$ Molecular Medicine Research Group, Hungarian Academy of Sciences,

Budapest, Hungary

Full list of author information is available at the end of the article
}

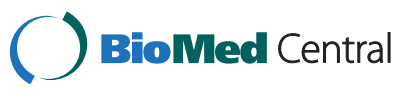

(c) 2015 Kalmár et al. Open Access This article is distributed under the terms of the Creative Commons Attribution 4.0 International License (http://creativecommons.org/licenses/by/4.0/), which permits unrestricted use, distribution, and reproduction in any medium, provided you give appropriate credit to the original author(s) and the source, provide a link to the Creative Commons license, and indicate if changes were made. The Creative Commons Public Domain Dedication waiver (http://creativecommons.org/publicdomain/zero/1.0/) applies to the data made available in this article, unless otherwise stated. 


\section{Background}

Colorectal cancer (CRC) is regarded as one of the most frequent malignant tumours globally [1]. This heterogeneous disease can develop through at least three distinct molecular pathways by which genetic and/or epigenetic dysregulation influences gene expression and protein levels finally leading to colorectal adenoma and carcinoma formation [2, 3]. One of the epigenetic alterations that can contribute to CRC formation is the abnormal DNA hypermethylation of promoters, resulting in reduced or absent gene expression [4]. DNA hypermethylation occurs at regulatory sites e.g. promoters in a tissue- and cancer type-specific manner [5]. Besides genetic alterations, DNA hypermethylation of tumour suppressor genes is a frequently detected mechanism behind the inactivation of these genes leading to tumour initiation [6]. Although more and more genes are associated with various types of cancers, our knowledge of DNA methylation markers in CRC development remains incomplete.

Another key posttrancriptional epigenetic regulator of gene expression, miRNA, regulates the stability and translation process of mRNAs. The expression of miRNAs has been shown to differ in colorectal tumours compared to healthy colon tissue specimens and on the basis of several experimental results they play role in colorectal cancer formation. Up- and downregulation of certain miRNAs was identified along the adenoma-carcinoma sequence of CRC and evidence supports the role of miRNAs in CRC development and progression as these small non-coding RNAs affect proliferation and invasion [7].

The identification of genes affected by epigenetic changes can be achieved using whole genome gene expression analysis [8]. DNA methylation and miRNA expression alterations can both lead to a certain degree of dowregulation of mRNA expression and consequently of protein levels, which can be confirmed by immunohistochemistry.

In the present study, our aims were (1) to identify DNA methylation markers in CRC samples on the basis of whole genome gene expression analysis and (2) to analyse the DNA methylation levels of these candidate marker along the colorectal adenoma-carcinoma sequence on colorectal adenoma and cancer samples. Furthermore, (3) our aim was to confirm the relationship between gene expression, DNA methylation status, miRNA expression and protein levels of the analysed candidate markers.

\section{Methods}

\section{Selection of candidate genes regulated by DNA methylation}

The selection of candidate genes was based on expression data generated from 147 colonic biopsy specimens (from 49 normal, 49 adenoma, and 49 CRC patients), laser capture microdissected colonic epithelial cells (from 6 NAT, 6 adenomas, and $6 \mathrm{CRC}$ ), analysed in a previous study by whole genome HGU133 Plus 2.0 microarrays (Affymetrix) $[8,9]$. These data files are available in the Gene Expession Omnibus database (http://www.ncbi.nlm.nih.gov/geo/) at GSE series accession numbers GSE4183 (8 normal, 15 adenoma and 15 CRC), GSE10714 (3 normal, 5 adenoma and 7 CRC), GSE37364 (38 normal, 29 adenoma and 27 CRC)) and GSE15960 (laser microdissected colonic epithelial cells from 6 normal, 6 adenoma and 6 CRC).Clinical data of patients involved in the analysed gene expression studies can be found in Additional file 1: Table S1.

Although the bioinformatic analysis and the candidate selection was based on previously performed and published raw gene expression data of HGU133 Plus 2.0 microarrays, the aim of the present study was substantially different from the previously published studies'. We aimed to identify genes with gradually altering expression in adenoma and tumour samples that can be potentially regulated by DNA methylation. The data sets GSE4183 [10], GSE10714 [11], GSE 37364 [9], and GSE15960 [8] were analysed to identify genes potentially regulated by DNA methylation. Transcripts with gradually decreasing or increasing expression along the adenoma-carcinoma sequence were selected on the basis of Kendall (tau coefficient) rank correlation analysis $(-0.5 \leq$ tau coefficient $\leq 0.5)$. DNA methylation analysis was performed for genes with $\mathrm{CpG}$ island(s) on the basis of in silico prediction by the CPG Plot EMBOSS application (http://www.ebi.ac.uk/Tools/seqstats/emboss_cpgplot/) [12].

Expression of the selected gene set was also analysed on gene expression data sets of human colorectal cell lines before and after DNA demethylation treatment with 5-Aza (GSE29060: $10 \mu \mathrm{M}$ 5-Aza treatment for $72 \mathrm{~h}$ on HT-29 cell line; GSE14526: $3 \mu \mathrm{M}$ 5-Aza treatment for $72 \mathrm{~h}$ on HCT116 and SW480 cell lines; GSE32323: $0.5 \mu \mathrm{M}$ 5-Aza treatment for $72 \mathrm{~h}$ on Colo32, HCT116, HT-29, RKO and SW480 cell lines.

Student's $t$-test and Benjamini-Hochberg method were applied in order to determine significance of gene expression and DNA methylation level comparisons $(p<0.05)$. For $\operatorname{logFc}$, abs (differences of average of intensity values) $>1$ threshold was applied.

\section{Tissue sample collection}

For DNA methylation analysis, tissue specimens were obtained from surgically removed colon tumours (moderately differentiated, Dukes B-C stages; MSS) $(n=15)$ and from histologically normal adjacent tissue (NAT) $(n=15)$ derived from the furthest available area away from the tumour. In addition, adenomas $(n=15)$ were also analysed, containing biopsy samples $(n=10)$ and fresh frozen tissue samples $(n=5)$, as well. Fresh frozen samples were snapfrozen in liquid nitrogen directly after surgery and were stored at $-80{ }^{\circ} \mathrm{C}$. Written informed consent was obtained from all patients; and 
the study was approved by the local ethics committee (Ethics Committee approval was obtained Nr.: TUKEB 2005/037 and TUKEB Nr.: 2008/69, Semmelweis University Regional and Institutional Committee of Science and Research Ethics, Budapest, Hungary). The study was performed according to the ethical standards of the revised version of Helsinki Declaration. Clinical data of patients involved in the study can be found in Additional file 2: Table S2.

\section{Laser capture microdissection, macrodissection}

Frozen tissue samples were embedded in OCT compound (Sakura Finetek, Japan). Then, $10 \mu \mathrm{m}$ cryosections were cut at $-20{ }^{\circ} \mathrm{C}$ in a cryostat instrument and mounted on PALM Membrane Slides 1.0 PEN (Carl Zeiss, Bernried, Germany). After fixation with $70 \%$ ethanol for $5 \mathrm{~min}$ and absolute ethanol for $2 \mathrm{~min}$, slides were stained with cresyl violet acetate (Sigma-Aldrich, St. Louis, USA). Colonic epithelial and stromal cells (approx. $10^{3}$ cells) were collected using the PALM Microbeam laser capture microdissection system (PALM, Bernried, Germany). Macrodissected samples were collected from cryosections after toluidine blue staining. Selected areas containing both stromal and epithelial cells were harvested by scratching the tissue slide with a single-use needle.

\section{DNA methylation analysis}

Bisulfite conversion

Bisulfite conversion was performed using the EZ DNA Methylation Direct Kit (Zymo Research) without prior DNA isolation. Proteinase $K$ digestion was performed in $20 \mu \mathrm{l}$ (according to Section I Protocol A) followed by bisulfite conversion. The elution volume was $20 \mu \mathrm{l}$.

\section{Bisulfite-specific PCR (BS-PCR)}

In silico $\mathrm{CpG}$ island prediction was performed by $\mathrm{CpG}$ Plot EMBOSS Application (http://www.ebi.ac.uk/Tools/ seqstats/emboss_cpgplot/). Bisulfite-specific PCR reactions were performed using primers designed with PyroMark Assay Design software (SW 2.0, Qiagen, Hilden, Germany) to be specific for non-CpG regions in order to amplify the bisulfite converted DNA samples without discriminating between methylated and non-methylated sequences (Table 1). PCR primers in the opposite direction of sequencing primers were biotin labelled. Primer specificities were tested in silico by BiSearch software (http://bisearch.enzim.hu) [13].

BS-PCR reactions were performed using AmpliTaq Gold 360 mastermix (2x) (Life Technologies, Carlsbad, USA), LightCycler 480 ResoLight Dye (40x) (Roche Applied Science), primer mix (200 nM final concentration), bisulfite converted DNA samples (approx. $10 \mathrm{ng}$ bcDNA/well) in $15 \mu \mathrm{l}$ final volume. Real-time PCR amplification was carried out with the following thermocycling conditions on the LightCycler 480 System: $95{ }^{\circ} \mathrm{C}$
Table 1 Genes analysed in the study. Genes with gradually decreasing or increasing expression along the adenomacarcinoma sequence with predictable CpG islands were selected on the basis of Kendall (tau coefficient) rank correlation analysis $(-0.5 \leq$ tau coefficient $\leq 0.5)$

\begin{tabular}{ll}
\hline Gene symbol & Gene name \\
\hline ALDH1A3 & aldehyde dehydrogenase 1 family, member A3 \\
BCL2 & B-cell CLL/lymphoma 2 \\
CDX1 & caudal type homeobox 1 \\
COL1A2 & collagen, type I, alpha 2 \\
CYP27B1 & cytochrome P450, family 27, subfamily B, polypeptide 1 \\
ENTPD5 & ectonucleoside triphosphate diphosphohydrolase 5 \\
FADS1 & fatty acid desaturase 1 \\
MAL & mal, T-cell differentiation protein \\
PRIMA1 & proline rich membrane anchor 1 \\
PTGDR & prostaglandin D2 receptor (DP) \\
PTGS2 & prostaglandin-endoperoxide synthase 2 \\
SFRP1 & secreted frizzled-related protein 1 \\
SFRP2 & secreted frizzled-related protein 2 \\
SOCS3 & suppressor of cytokine signaling 3 \\
SULF1 & sulfatase 1 \\
SULT1A1 & sulfotransferase family, cytosolic, 1A, phenol-preferring, \\
THBS2 & member 1 \\
TIMP1 & thrombospondin 2 \\
\hline
\end{tabular}

for $10 \mathrm{~min}$, then $95{ }^{\circ} \mathrm{C}$ for $30 \mathrm{~s}, 60{ }^{\circ} \mathrm{C}$ with a $0.4{ }^{\circ} \mathrm{C}$ decrease/cycle for $30 \mathrm{~s}, 72{ }^{\circ} \mathrm{C}$ for $30 \mathrm{~s}$ for 10 touchdown cycles, followed by the amplification at $95{ }^{\circ} \mathrm{C}$ for $30 \mathrm{~s}, 56^{\circ} \mathrm{C}$ for $30 \mathrm{~s}$, and $72^{\circ} \mathrm{C}$ for $30 \mathrm{~s}$ in 40 cycles.

Providing single-base resolution information about the methylation status of a $\mathrm{CpG}$ island direct sequencing is one of the most robust methods to analyse BS-PCR products. After bisulfite treatment and BS-PCR, all cytosines are converted to thymines except for those originally methylated. Two different pyrosequencing technologies were applied to analyse DNA methylation of BS-PCR products i.e. the Qiagen PyroMark System and the Roche GS Junior System utilising the 454 technology. The read length of the different technologies differs. With the PyroMark system sequences, up to $60 \mathrm{bp}$ can be analysed, while up to $400 \mathrm{bp}$ read length could be achieved with the 454 technology.

\section{PyroMark Q24 sequencing}

Pyrosequencing was performed on a PyroMark Q24 instrument (Qiagen) using PyroMark Gold Q24 Reagents (Qiagen) according to the manufacturer's recommendations. Purification and subsequent processing of the biotinylated single-stranded DNA were performed in two consecutive runs by applying two different sequencing primers in order to cover more $\mathrm{CpG}$ sites in the 
amplicons $[14,15]$. Sequencing results were analysed using the PyroMark Q24 software v2.0.6 (Qiagen).

\section{GS Junior sequencing}

Library preparation with ligated adaptors and emulsionPCR amplification were as described in "Guidelines for Amplicon Experimental Design". The concentrations of BS-PCR amplicons were measured by Qubit fluorometer with High Sensitivity dsDNA reagent (Life Technologies). Amplicons belonging to the same sample were pooled at an equimolar ratio and PCR products were purified with AMPure beads (Agencourt, Beckman Coulter Genomics, Pasadena, USA) according to the manufacturer's standard protocol. The Agilent Bioanalyzer was used with the High Sensitivity DNA Chip (Agilent, Santa Clara, USA) to assess sample quality. Fragment End Repair was performed using the GS FLX Titanium Rapid Library Preparation Kit (Rapid Library Preparation Method Manual 3.2). RL MID Adaptor Ligation was carried out using GS FLX Titanium Rapid Library Preparation Kit (Rapid Library Preparation Method Manual 3.4). After ligation, purification of amplicon libraries was performed with AMPure beads, and assessment of library quality was done using the Agilent Bioanalyzer with High Sensitivity DNA Chip. Library quantification was performed based on fluorometric measurements with Qubit High Sensitivity dsDNA reagent. Equimolar mixing of the libraries was performed by MIDs identifying different samples with different MID adaptors. Amplicon library pools were then amplified by emPCR at a 0.5 DNA molecule per bead ratio using the Lib-L emPCR Kit. Since amplicon lengths were short, the emPCR procedure was performed with reduced Amp Primer quantity (emPCR Amplification Method Manual Lib-L, GS Junior Titanium Series, Live Amp Mix for paired end libraries). Bead enrichment and sequencing were performed using the GS Junior Titanium Sequencing Kit and the method described in the Sequencing Method Manual, GS FLX Titanium Series.

The Smith-Waterman algorithm with Gotoh's improvement was used for matching the reads to template sequences in the JAligner software package $[16,17]$. As 454 technology can result in sequencing errors with homopolymer stretches e.g. in bisulfite-sequencing templates [18], gaps or insertions were frequently observed in the sequenced reads. Reads with a minimum of $80 \%$ of maximum alignment score were analysed further, after which the actual nucleotides at the potential methylation sites were summarised.

\section{miRNA analysis}

miRNA analysis was performed on an independent formalin-fixed, paraffin-embedded (FFPE) sample set including CRC $(n=3)$, adenomas $(n=3)$ and NAT $(n=3)$ samples. miRNA isolation was performed with the High
Pure miRNA kit (Roche) and the expression of approximate 800 miRNA were assessed on Human Panel I+ II (Exiqon) with the miRCURY ${ }^{\mathrm{TM}}$ Universal RT microRNA PCR protocol according to the manufacturer's instructions. Normalisation of raw $\mathrm{Ct}$ data was performed with interplate calibrators followed by miR-423-5p, as a housekeeping gene expressed at relatively constant levels in our analysed samples. In silico miRNA prediction was performed for all analysed genes using the miRWALK database prediction algorithm including validated mRNA targets [19] in order to select experimentally verified miRNA interaction information associated with genes, pathways, organs, diseases, cell lines, OMIM disorders, and literature on miRNAs. Subsequently, expression of selected miRNAs in normal, adenoma and cancer samples was compared.

\section{Immunohistochemistry}

Among the analysed 18 genes, SFRP1 protein level was analysed because of the special interest of our working group. Surgically removed colonic tissues from NAT $(n=10)$, AD $(n=10)$, and CRC specimens $(n=10)$ were fixed in formalin and embedded in paraffin and tissue microarrays (TMA) were constructed. Four $\mu \mathrm{m}$ sections were cut, deparaffinised, and rehydrated. For SFRP1 staining, antigen retrieval was performed in TRIS EDTA buffer ( $\mathrm{pH}$ 9.0) using a microwave (900 W for $10 \mathrm{~min}, 340 \mathrm{~W}$ for $40 \mathrm{~min}$ ). Samples were incubated with anti-SFRP1 rabbit polyclonal antibody (ab4193, Abcam, Cambridge, UK) diluted 1:800 for $60 \mathrm{~min}$ at $37^{\circ} \mathrm{C}$. EnVision + HRP system (Labeled Polymer AntiMouse, K4001, Dako) and diaminobenzidine-hydrogen peroxidase-chromogen substrate system (Cytomation Liquid DAB + Substrate Chromogen System, K3468, Dako) were used with hematoxylin counterstaining. Slides were digitalised using the Pannoramic Scanner p250 Flash instrument (software version 1.11.25.0, 3DHISTECH Ltd., Budapest, Hungary), and analysed with a digital microscope software (Pannoramic Viewer, v. 1.11.43.0. 3DHISTECH Ltd., Budapest, Hungary). The semiquantitative Quick-score (Q) method was applied for SFRP1 protein level alteration analysis. Every TMA core was scored by multiplying the percentage of positive cells by the given intensity value ( 0 for no staining, +1 for weak, +2 for moderate, and +3 for strong diffuse immunostaining).

\section{Results}

\section{Gene expression analysis}

Genes potentially regulated by DNA methylation were selected on the basis of whole genome gene expression data from previously performed microarray experiments of 49 normal, 49 adenoma, and 49 tumour biopsy samples [9]. Based on Kendall analysis, a set of 18 transcripts was selected showing continuously altering expression $(p \leq 0.01)$ in the biopsy samples along the 
adenoma-carcinoma sequence (Table 1). Along colorectal adenoma-carcinoma progression, the following genes showed downregulation: BCL2, CDX1, ENTPD5, MAL, PRIMA1, PTGDR, SFRP1, and SULT1A1 while the following genes showed upregulation: ALDH1A3, COL1A2, CYP27B1, FADS1, PTGS2, SFRP2, SOCS3, SULF1, THBS2, and TIMP1. Gene expression alteration of $B C L 2, C D X 1$, CYP27B1, ENTPD5, MAL, PRIMA1, PTGDR, PTGS2, SFRP1, SOCS3 SULT1A1, and TIMP1 were found to be significant $(p<0.05)$ in the adenoma versus healthy and also in the tumour versus healthy comparison. In addition, ALDH1A3, COL1A2, FADS1, SFRP2, SULF1, and THBS2 were found to be significantly $(p<0.01)$ differentially expressed in tumour samples but not in adenomas compared to healthy samples (Fig. 1, Table 2, Additional file 3: Figure S1, Additional file 4: Table S3).

In order to investigate the cellular origin of altered gene expression of the analysed transcript set during colorectal cancer formation, laser capture microdissection was applied to separate epithelial and stromal cells from the colonic mucosa. Significantly altered expression $(p<0.05)$ of SOCS3 and PRIMA1 could be detected in epithelial cells from normal versus adenomatous samples. Gene expression changes of BCL2, CYP27B1, COL1A2, FADS1, and SULT1A1 were significant $(p<0.05)$ only in tumours compared to healthy samples, while CDX1, ENTPD5, PTGDR , and TIMP1 showed gene expression difference in both normal vs. adenoma and normal vs. tumour comparisons (Fig. 1, Table 2, Additional file 4: Table S3).

No significant gene expression alterations could be detected in the stromal cells isolated from adenomas compared to the normals, but COL1A2, FADS1, MAL, PRIMA1, SULF1, THBS2, TIMP1 genes' transcripts showed significant differences $(p<0.05)$ in $\operatorname{logFc}$ values for the tumour versus normal comparison (Fig. 1; Additional file 4: Table S3). As stromal cells showed the fewest gene expression alterations, we further focused on biopsy and laser microdissected epithelial samples.

\section{Demethylation treatment on colon adenocarcinoma cell lines}

Gene expression of the selected marker set was analysed on data sets containing control and 5-Aza treated colon adenocarcinoma cell lines. According to GSE29060 data, in HT-29 adenocarcinoma cells after a demethylation treatment 4 transcripts showed a minimally decreased expression (TIMP1, FADS1, CYP27B and SULT1A1), while PTGS2 was found to be upregulated. HCT-116 cells showed higher re-expression of the selected genes, as PTGS2, THBS2 and TIMP1 also showed upregulation $\left(1<\log \mathrm{Fc}_{\text {control-treated }}\right)$ and TIMP1 was also upregulated in 5-Aza treated SW480 cells according to GSE14526. Among the 5 CRC cell lines of GSE32323 SULT1A1 in Colo32 cells, PTGS2 in HCT-116 cells, ALDH1A3 and SOCS3 in HT-29 cells and ALDH1A3 and TIMP1 in SW480 cells showed remarkable upregulation after demethylation treatment (Fig. 2, Additional file 4: Table S3).

\section{DNA methylation analysis}

DNA methylation was assessed in human colonic samples using two different pyrosequencing systems. Firstly, routinely collected biopsy samples and macrodissected specimens naturally containing both epithelial and stromal cells were analysed. Among the 18 analysed markers (Table 1), DNA methylation was significantly $(p<0.05)$ altered for six loci belonging to four genes, in which COL1A2, SFRP2, SOCS3 showed hypermethylation and THBS2 showed hypomethylation both in $\mathrm{AD}$ and in CRC samples compared to NAT. Three additional genes, BCL2, PRIMA1, and PTGDR showed hypermethylation only in tumour samples (Table 3, Additional file 5: Figure S2).

Interestingly, two of the analysed regions in the THBS2 promoter conferred hypomethylation along tumour formation, while the third locus examined showed significant hypermethylation in tumours compared to NAT.
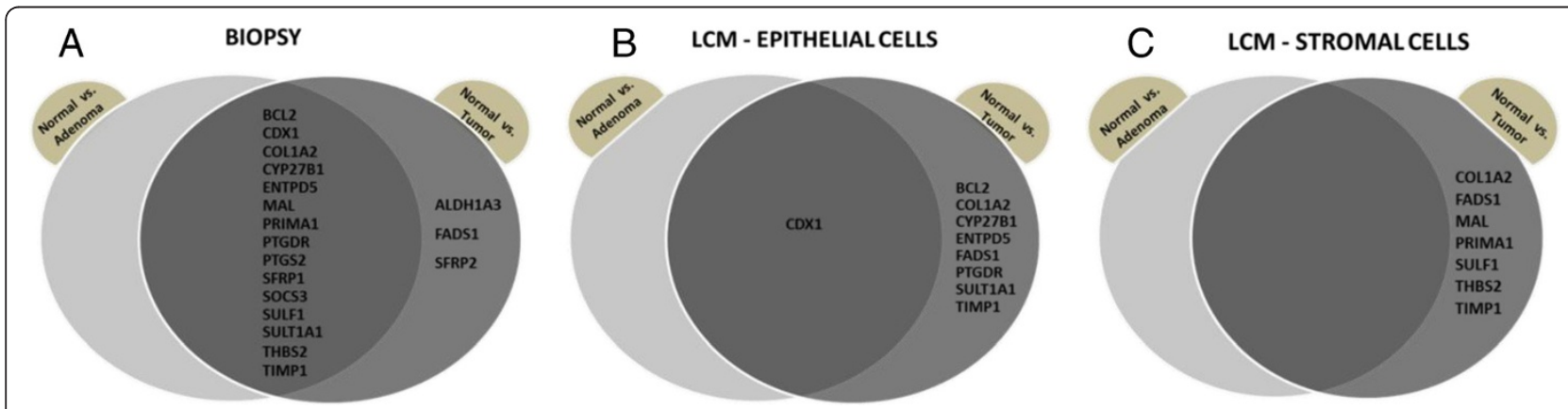

Fig. 1 Summary of genes with altered expression levels in the analysed samples. Venn diagrams display genes that exhibit significantly altered gene expression patterns $(p<0.05)$ in $(\mathbf{a})$ colon biopsy samples, $(\mathbf{b})$ laser capture microdissected $(\mathrm{LCM})$ epithelial cells, and (c) stromal cells in the normal versus adenoma, normal versus tumour comparisons and their intersections. The majority of gene expression changes could be detected in biopsy samples, while LCM epithelial and stromal cells show fewer altered transcript levels, primarily in normal vs. tumour comparison 
Table 2 Gene expression data of biopsies and laser microdissected (LCM) colon epithelial cells

\begin{tabular}{|c|c|c|c|c|c|c|}
\hline & \multirow{2}{*}{$\begin{array}{l}\text { Normal } \\
\text { Mean normalised intensity } \\
\text { values } \pm \text { SD }\end{array}$} & \multirow{2}{*}{$\begin{array}{l}\text { Adenoma } \\
\text { Mean normalised intensity } \\
\text { values } \pm \text { SD }\end{array}$} & \multirow{2}{*}{$\begin{array}{l}\text { CRC } \\
\text { Mean normalised intensity } \\
\text { values } \pm \text { SD }\end{array}$} & \multirow{2}{*}{$\begin{array}{l}P \text {-value } \\
\text { (N vs. Ad) }\end{array}$} & \multirow{2}{*}{$\begin{array}{l}P \text {-value } \\
\text { (N vs. CRC) }\end{array}$} & \multirow{2}{*}{$\begin{array}{l}P \text {-value } \\
\text { (Ad vs. CRC) }\end{array}$} \\
\hline & & & & & & \\
\hline \multicolumn{7}{|l|}{ Biopsy samples } \\
\hline 203180_at (ALDH1A3) & $6.36 \pm 0.92$ & $6.53 \pm 0.86$ & $7.29 \pm 1.45$ & 0.34 & $p<0.01$ & $p<0.01$ \\
\hline 203685_at (BCL2) & $8.90 \pm 0.52$ & $7.96 \pm 1.08$ & $6.98 \pm 1.22$ & $p<0.01$ & $p<0.01$ & $p<0.01$ \\
\hline 206430_at (CDX1) & $11.70 \pm 0.28$ & $11.17 \pm 0.35$ & $10.84 \pm 0.73$ & $p<0.01$ & $p<0.01$ & $p<0.01$ \\
\hline 202404_s_at (COL1A2) & $9.75 \pm 0.78$ & $10.25 \pm 1.11$ & $12.31 \pm 1.67$ & 0.01 & $p<0.01$ & $p<0.01$ \\
\hline 205676_at (CYP27B1) & $2.55 \pm 0.10$ & $2.88 \pm 0.54$ & $3.15 \pm 0.95$ & $p<0.01$ & $p<0.01$ & 0.09 \\
\hline 1554094_at (ENTPD5) & $6.41 \pm 0.70$ & $4.56 \pm 0.79$ & $4.15 \pm 1.29$ & $p<0.01$ & $p<0.01$ & 0.06 \\
\hline 208963_x_at (FADS1) & $4.82 \pm 0.70$ & $5.05 \pm 1.14$ & $6.36 \pm 1.65$ & 0.22 & $p<0.01$ & $p<0.01$ \\
\hline 204777_s_at (MAL) & $6.02 \pm 0.62$ & $4.86 \pm 0.37$ & $4.88 \pm 0.59$ & $p<0.01$ & $p<0.01$ & 0.86 \\
\hline 230087_at (PRIMA1) & $4.09 \pm 0.97$ & $2.20 \pm 0.61$ & $2.31 \pm 0.83$ & $p<0.01$ & $p<0.01$ & 0.47 \\
\hline 234165_at (PTGDR) & $5.84 \pm 1.08$ & $3.91 \pm 1.75$ & $2.81 \pm 0.85$ & $p<0.01$ & $p<0.01$ & $p<0.01$ \\
\hline 204748_at (PTGS2) & $4.96 \pm 1.33$ & $6.84 \pm 2.50$ & $9.88 \pm 2.74$ & $p<0.01$ & $p<0.01$ & $p<0.01$ \\
\hline 202036_s_at (SFRP1) & $4.05 \pm 1.47$ & $2.18 \pm 0.62$ & $2.51 \pm 1.28$ & $p<0.01$ & $p<0.01$ & 0.11 \\
\hline 223121_s_at (SFRP2) & $2.87 \pm 0.11$ & $2.92 \pm 0.28$ & $3.94 \pm 1.74$ & 0.29 & $p<0.01$ & $p<0.01$ \\
\hline 227697_at (SOCS3) & $6.10 \pm 1.11$ & $7.42 \pm 1.65$ & $9.81 \pm 2.06$ & $p<0.01$ & $p<0.01$ & $p<0.01$ \\
\hline 212353_at (SULF1) & $6.29 \pm 1.04$ & $7.12 \pm 1.16$ & $9.23 \pm 2.15$ & $p<0.01$ & $p<0.01$ & $p<0.01$ \\
\hline 215299_x_at (SULT1A1) & $11.94 \pm 0.53$ & $10.40 \pm 0.85$ & $10.34 \pm 0.95$ & $p<0.01$ & $p<0.01$ & 0.72 \\
\hline 203083_at (THBS2) & $2.61 \pm 0.44$ & $3.46 \pm 1.54$ & $7.67 \pm 3.13$ & $p<0.01$ & $p<0.01$ & $p<0.01$ \\
\hline 201666_at (TIMP1) & $10.29 \pm 0.75$ & $12.20 \pm 0.69$ & $12.80 \pm 1.04$ & $p<0.01$ & $p<0.01$ & $p<0.01$ \\
\hline \multicolumn{7}{|c|}{ LCM - colon epithelial cells } \\
\hline 203180_at (ALDH1A3) & $3.44 \pm 0.83$ & $3.35 \pm 0.34$ & $3.61 \pm 0.73$ & 0.80 & 0.72 & 0.45 \\
\hline 203685_at (BCL2) & $7.02 \pm 0.64$ & $6.94 \pm 1.56$ & $4.52 \pm 2.00$ & 0.91 & $p<0.05$ & $p<0.05$ \\
\hline 206430_at (CDX1) & $10.35 \pm 0.57$ & $9.51 \pm 0.47$ & $9.38 \pm 0.53$ & $p<0.05$ & $p<0.05$ & 0.65 \\
\hline 202404_s_at (COL1A2) & $4.27 \pm 1.50$ & $3.28 \pm 0.69$ & $7.55 \pm 1.02$ & 0.18 & $p<0.01$ & $p<0.01$ \\
\hline 205676_at (CYP27B1) & $2.75 \pm 0.04$ & $2.79 \pm 0.05$ & $3.07 \pm 0.24$ & 0.10 & $p<0.01$ & $p<0.05$ \\
\hline 1554094_at (ENTPD5) & $4.51 \pm 0.68$ & $3.80 \pm 0.69$ & $2.51 \pm 0.08$ & 0.10 & $p<0.01$ & $p<0.01$ \\
\hline 208963_x_at (FADS1) & $3.24 \pm 0.21$ & $3.18 \pm 0.17$ & $4.44 \pm 1.49$ & 0.57 & 0.08 & 0.07 \\
\hline 204777_s_at (MAL) & $2.38 \pm 0.17$ & $2.30 \pm 0.00$ & $2.31 \pm 0.02$ & 0.29 & 0.34 & 0.30 \\
\hline 230087_at (PRIMA1) & $2.63 \pm 0.29$ & $3.88 \pm 1.08$ & $2.43 \pm 0.12$ & $p<0.05$ & 0.14 & $p<0.01$ \\
\hline 234165_at (PTGDR) & $4.71 \pm 0.73$ & $3.77 \pm 1.02$ & $2.39 \pm 0.09$ & 0.10 & $p<0.01$ & $p<0.01$ \\
\hline 204748_at (PTGS2) & $2.61 \pm 0.15$ & $2.68 \pm 0.24$ & $2.51 \pm 0.04$ & 0.59 & 0.14 & 0.13 \\
\hline 202036_s_at (SFRP1) & $2.71 \pm 0.35$ & $2.76 \pm 0.33$ & $2.54 \pm 0.00$ & 0.80 & 0.27 & 0.13 \\
\hline 223121_s_at (SFRP2) & $2.35 \pm 0.09$ & $2.36 \pm 0.16$ & $2.30 \pm 0.00$ & 0.81 & 0.28 & 0.34 \\
\hline 227697_at (SOCS3) & $4.97 \pm 1.91$ & $2.82 \pm 0.43$ & $4.33 \pm 1.69$ & $p<0.05$ & 0.55 & 0.06 \\
\hline 212353_at (SULF1) & $3.08 \pm 0.81$ & $2.73 \pm 0.09$ & $3.99 \pm 1.44$ & 0.32 & 0.21 & 0.06 \\
\hline 215299_x_at (SULT1A1) & $9.35 \pm 0.31$ & $8.57 \pm 1.16$ & $7.20 \pm 0.95$ & 0.14 & $p<0.01$ & $p<0.05$ \\
\hline 203083_at (THBS2) & $2.58 \pm 0.14$ & $2.53 \pm 0.00$ & $3.54 \pm 1.43$ & 0.48 & 0.13 & 0.12 \\
\hline 201666_at (TIMP1) & $4.11 \pm 1.06$ & $6.54 \pm 1.62$ & $7.85 \pm 0.57$ & $p<0.05$ & $p<0.01$ & 0.09 \\
\hline
\end{tabular}

Unsupervised clustering of genes with DNA hypermethylation

Unsupervised hierarchical clustering of DNA methylation data revealed three groups of markers in biopsy and macrodissected sample groups. The first group of genes (SFRP2, COL1A2, THBS2, SOCS3, CYP27B1, SULT1A1, PRIMA1 and MAL) showed a relatively high degree of DNA methylation already in $\mathrm{AD}$ and also in CRC 


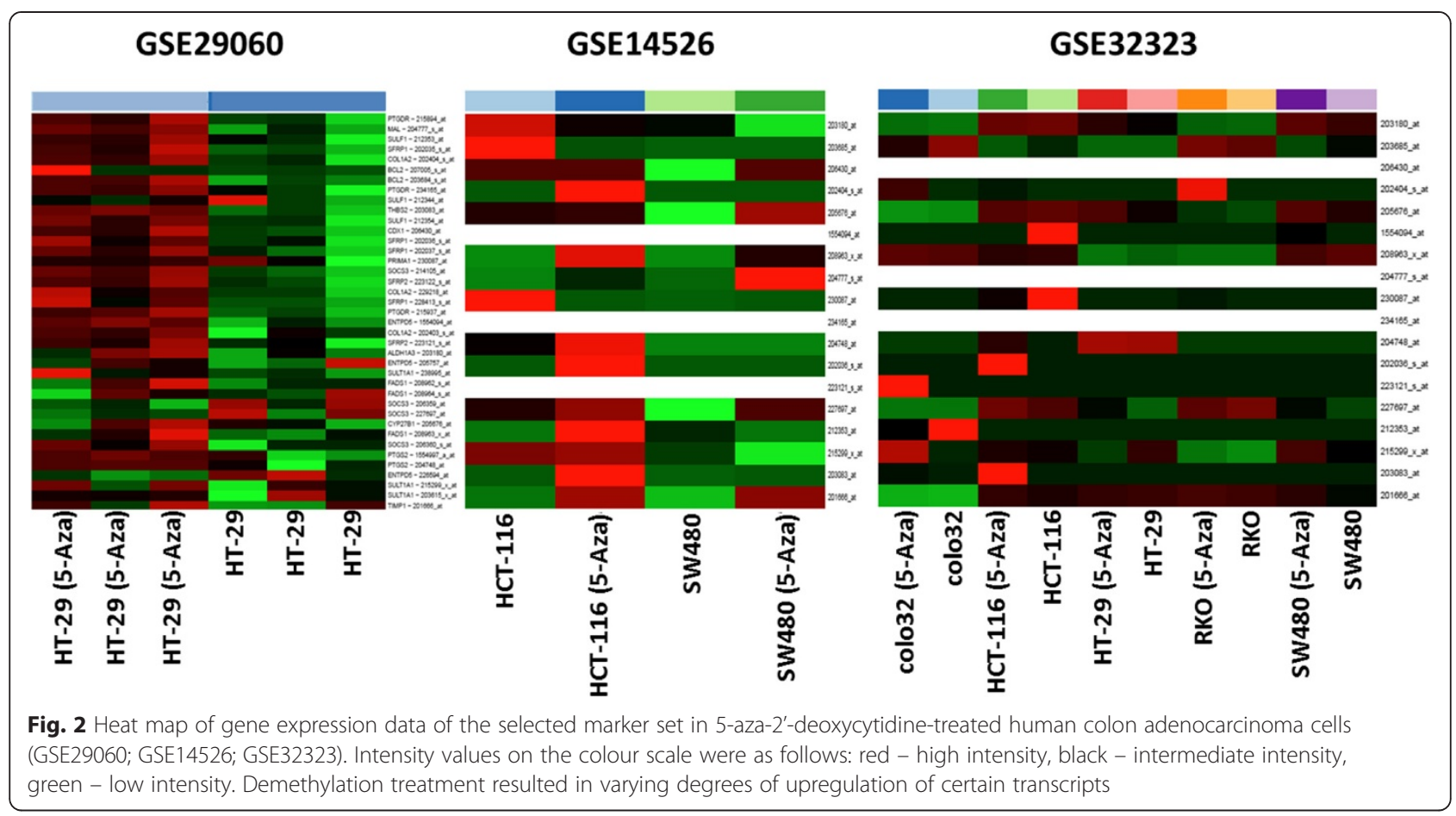

samples. The second group included most markers and did not show remarkable difference among different sample groups, while the third minor cluster included only two THBS2 loci with high methylation levels across all samples (Fig. 3a). Unsupervised hierarchical clustering of LCM epithelial cells revealed similar relationships to those in biopsy and macrodissected samples above. Certain genes showed relatively high DNA methylation levels in both biopsies and epithelial cells in adenoma and cancer cases, as PRIMA1, SFRP1, SFRP2, MAL, SOCS3, CYP27B1, COL1A2 and SULT1A1. THBS2 showed high methylation levels across all samples. The second major marker group included most genes and did not show remarkable difference between the different sample groups (Fig. 3b).

\section{miRNA analysis}

We used the miRWALK database to predict miRNAs that could target genes of our selected set. Multiple miRNAs could be predicted using the miRWALK 'Validated Target' in silico searching application. Certain groups of miRNAs were predicted to target more genes analysed in our present study; miR-21 (predicted for BCL2, MAL, PTGS2, SFRP1, SOCS3) expression was found to be remarkably upregulated in CRC compared to NAT (Fig. 4). Furthermore, miR-21* (predicted for BCL2, MAL, SFRP1, SOCS3, PTGS2), miR-181c (predicted for $A L D H 1 A 3, B C L 2, M A L$ ), and let-7i* (predicted for $B C L 2$, CYP27B1, and SOCS3) were also found to be upregulated in $\mathrm{AD}$ and $\mathrm{CRC}$ samples (Fig. 4).

\section{Immunohistochemistry}

Colonic FFPE tissue samples were immunostained for SFRP1. In NAT epithelium, moderate diffuse cytoplasmic staining $(+2)$ could be detected (Fig. 5a, white arrows) in contrast to adjacent myofibroblasts (we identified they by their localisation and morphology) with strong diffuse immunostaining $(+3)$ (Fig. 5a, red arrows). In tubular $\mathrm{AD}$ samples, weak diffuse cytoplasmic protein expression $(+1)$ was accompanied by strong and spotted immunostaining $(+2 /+3)$ (Fig. 5b). The majority of CRC cases ( 9 out of 10 cases) showed weak $(+1)$ or no (0) SFRP1 immunostaining (Fig. 5c). According to Q-score values used for semiquantitative immunohistochemistry analysis, the overall SFRP1 protein expression decreased along the colorectal adenoma-carcinoma sequence (Fig. 5).

\section{Discussion}

The goal of this study was to identify DNA methylation and miRNA markers associated with the sequence of adenoma-carcinoma formation leading to CRC. The candidate markers were selected based on whole genome gene expression array data, DNA methylation analysis, and in silico prediction and validation of miRNA expression.

The study identified set of 18 transcripts showing continuous gene expression alterations that correlated with CRC progression. Microarray experiments revealed 12 genes (BCL2, CDX1, CYP27B1, ENTPD5, MAL, PRIMA1, PTGDR, PTGS2, SFRP1, SOCS3, SULT1A1, and TIMP1) with significantly different transcriptional activities in $\mathrm{AD}$ compared to NAT controls, while 6 genes (ALDH1A3, 
Table 3 DNA methylation data of biopsies, macrodissected samples and laser microdissected (LCM) colon epithelial cells

\begin{tabular}{|c|c|c|c|c|c|c|}
\hline & \multirow{2}{*}{$\begin{array}{l}\text { Normal } \\
\text { Mean DNA methylation } \\
\% \pm \text { SD }\end{array}$} & \multirow{2}{*}{$\begin{array}{l}\text { Adenoma } \\
\text { Mean DNA methylation } \\
\% \pm \text { SD }\end{array}$} & \multirow{2}{*}{$\begin{array}{l}\text { CRC } \\
\text { Mean DNA methylation } \\
\% \pm \mathrm{SD}\end{array}$} & \multirow{2}{*}{$\begin{array}{l}P \text {-value } \\
\text { (N vs. Ad) }\end{array}$} & \multirow{2}{*}{$\begin{array}{l}P \text {-value } \\
\text { (N vs. CRC) }\end{array}$} & \multirow{2}{*}{$\begin{array}{l}P \text {-value } \\
\text { (Ad vs. CRC) }\end{array}$} \\
\hline & & & & & & \\
\hline \multicolumn{7}{|l|}{ Biopsy samples } \\
\hline ALDH1A3_assay 1 & $4.33 \pm 2.23$ & $3.59 \pm 1.92$ & $5.74 \pm 6.26$ & 0.31 & 0.36 & 0.21 \\
\hline BCL2_assay 1 & $3.22 \pm 1.12$ & $3.50 \pm 2.21$ & $9.74 \pm 13.41$ & 0.63 & $p<0.05$ & 0.09 \\
\hline BCL2_assay 2 & $0.91 \pm 0.72$ & $0.42 \pm 0.41$ & $0.73 \pm 0.59$ & $p<0.05$ & 0.44 & 0.11 \\
\hline CDX1_assay 1 & $21.96 \pm 9.38$ & $19.41 \pm 8.76$ & $16.01 \pm 9.83$ & 0.42 & 0.08 & 0.32 \\
\hline COL1A2 assay 2 & $22.67 \pm 5.62$ & $37.37 \pm 14.36$ & $39.52 \pm 18.02$ & $p<0.01$ & $p<0.01$ & 0.72 \\
\hline COL1A2_assay 1 & $8.65 \pm 3.63$ & $9.77 \pm 6.13$ & $15.31 \pm 12.57$ & 0.51 & $p<0.05$ & 0.14 \\
\hline CYP27B1_assay 1 & $10.71 \pm 3.14$ & $8.53 \pm 4.19$ & $11.37 \pm 6.76$ & 0.09 & 0.71 & 0.18 \\
\hline CYP27B1_assay 2 & $4.03 \pm 4.16$ & $2.71 \pm 1.69$ & $6.45 \pm 10.56$ & 0.26 & 0.36 & 0.19 \\
\hline CYP27B1_assay 4 & $45.12 \pm 2.66$ & $44.50 \pm 2.08$ & $46.70 \pm 8.04$ & 0.46 & 0.42 & 0.31 \\
\hline ENTPD5_assay 1 & $2.17 \pm 0.62$ & $1.78 \pm 0.91$ & $2.93 \pm 3.32$ & 0.15 & 0.35 & 0.20 \\
\hline FADS1_assay 1 & $0.75 \pm 0.44$ & $0.46 \pm 0.23$ & $6.98 \pm 10.82$ & $p<0.05$ & $p<0.05$ & $p<0.05$ \\
\hline MAL_assay 1 & $16.46 \pm 16.12$ & $38.87 \pm 26.52$ & $50.42 \pm 26.99$ & $p<0.01$ & $p<0.01$ & 0.25 \\
\hline PRIMA1_assay 1 & $7.25 \pm 3.15$ & $9.88 \pm 10.60$ & $28.91 \pm 22.65$ & 0.30 & $p<0.01$ & $p<0.01$ \\
\hline PRIMA1_assay 2 & $3.99 \pm 1.32$ & $6.49 \pm 5.60$ & $22.29 \pm 20.14$ & 0.06 & $p<0.01$ & $p<0.01$ \\
\hline PRIMA1_assay 3 & $37.96 \pm 13.57$ & $48.13 \pm 20.69$ & $56.43 \pm 21.17$ & 0.11 & $p<0.01$ & 0.30 \\
\hline PRIMA1_assay 4 & $8.30 \pm 7.95$ & $17.78 \pm 13.26$ & $26.82 \pm 25.00$ & $p<0.05$ & $p<0.01$ & 0.23 \\
\hline PTGDR assay 1 & $5.79 \pm 1.84$ & $4.09 \pm 1.85$ & $11.12 \pm 9.36$ & $p<0.05$ & $p<0.05$ & $p<0.01$ \\
\hline PTGDR assay 2 & $11.71 \pm 3.51$ & $8.01 \pm 4.50$ & $15.58 \pm 6.48$ & $p<0.05$ & $p<0.05$ & $p<0.01$ \\
\hline PTGDR_assay 3 & $6.47 \pm 9.27$ & $3.61 \pm 4.63$ & $10.47 \pm 9.51$ & 0.28 & 0.22 & $p<0.05$ \\
\hline PTGS2_assay 1 & $8.82 \pm 3.47$ & $12.15 \pm 15.01$ & $10.80 \pm 13.16$ & 0.34 & 0.52 & 0.80 \\
\hline PTGS2_assay 2 & $4.33 \pm 9.01$ & $5.83 \pm 10.49$ & $5.64 \pm 8.48$ & 0.65 & 0.67 & 0.96 \\
\hline SFRP1_assay 1 & $39.60 \pm 18.46$ & $60.82 \pm 20.41$ & $54.49 \pm 18.47$ & $p<0.01$ & $p<0.05$ & 0.38 \\
\hline SFRP2_assay 1 & $14.84 \pm 4.38$ & $38.52 \pm 20.06$ & $44.44 \pm 20.05$ & $p<0.01$ & $p<0.01$ & 0.43 \\
\hline SFRP2_assay 2 & $20.14 \pm 4.48$ & $39.33 \pm 17.77$ & $48.04 \pm 16.20$ & $p<0.01$ & $p<0.01$ & 0.17 \\
\hline SOCS3_assay 1 & $4.96 \pm 1.52$ & $7.57 \pm 6.18$ & $12.16 \pm 12.01$ & 0.08 & $p<0.05$ & 0.20 \\
\hline SOCS3_assay 2 & $18.24 \pm 7.68$ & $49.27 \pm 20.49$ & $49.43 \pm 18.81$ & $p<0.01$ & $p<0.01$ & 0.98 \\
\hline SOCS3_assay 3 & $8.82 \pm 16.20$ & $21.75 \pm 21.72$ & $25.79 \pm 22.22$ & 0.05 & $p<0.05$ & 0.62 \\
\hline SULF1_assay 1 & $5.32 \pm 2.16$ & $6.80 \pm 11.30$ & $9.60 \pm 8.91$ & 0.57 & $p<0.05$ & 0.46 \\
\hline SULF1_assay 2 & $4.60 \pm 4.02$ & $7.98 \pm 10.78$ & $11.28 \pm 14.82$ & 0.21 & 0.06 & 0.49 \\
\hline SULT1A1_assay 1 & $5.51 \pm 4.35$ & $3.25 \pm 1.99$ & $7.58 \pm 9.46$ & 0.07 & 0.39 & 0.09 \\
\hline SULT1A1_assay 2 & $42.68 \pm 5.54$ & $44.86 \pm 9.49$ & $48.80 \pm 10.07$ & 0.40 & $p<0.05$ & 0.28 \\
\hline SULT1A1_assay 3 & $3.11 \pm 2.94$ & $2.14 \pm 1.66$ & $6.34 \pm 6.55$ & 0.26 & 0.06 & $p<0.05$ \\
\hline THBS2_assay 1 & $18.17 \pm 5.03$ & $26.47 \pm 13.79$ & $28.36 \pm 16.92$ & $p<0.05$ & $p<0.05$ & 0.74 \\
\hline THBS2_assay 2 & $91.32 \pm 2.37$ & $85.64 \pm 6.49$ & $83.73 \pm 6.83$ & $p<0.01$ & $p<0.01$ & 0.44 \\
\hline THBS2_assay 3 & $89.68 \pm 1.80$ & $87.51 \pm 3.55$ & $83.02 \pm 6.69$ & $p<0.05$ & $p<0.01$ & $p<0.05$ \\
\hline THBS2_assay 4 & $22.32 \pm 10.74$ & $27.97 \pm 13.58$ & $25.47 \pm 15.20$ & 0.18 & 0.48 & 0.64 \\
\hline TIMP1_assay 1 & $19.54 \pm 14.39$ & $16.65 \pm 14.45$ & $13.96 \pm 10.07$ & 0.56 & 0.21 & 0.56 \\
\hline \multicolumn{7}{|c|}{ LCM - colon epithelial cells } \\
\hline ALDH1A3_assay 1 & $8.30 \pm 3.96$ & $4.02 \pm 2.56$ & $3.60 \pm 3.49$ & 0.08 & 0.08 & 0.83 \\
\hline BCL2_assay 1 & $3.14 \pm 1.18$ & $3.30 \pm 1.19$ & $4.26 \pm 2.58$ & 0.84 & 0.40 & 0.47 \\
\hline BCL2_assay 2 & $4.53 \pm 7.59$ & $0.32 \pm 0.35$ & $0.33 \pm 0.47$ & 0.24 & 0.30 & 0.99 \\
\hline
\end{tabular}


Table 3 DNA methylation data of biopsies, macrodissected samples and laser microdissected (LCM) colon epithelial cells (Continued)

\begin{tabular}{|c|c|c|c|c|c|c|}
\hline CDX1_assay 1 & $11.26 \pm 19.16$ & $1.64 \pm 1.16$ & $2.43 \pm 2.43$ & 0.29 & 0.40 & 0.54 \\
\hline COL1A2 assay 2 & $19.18 \pm 6.95$ & $61.72 \pm 18.25$ & $53.46 \pm 18.52$ & $p<0.01$ & $p<0.01$ & 0.50 \\
\hline COL1A2_assay 1 & $6.46 \pm 3.34$ & $14.06 \pm 6.37$ & $22.84 \pm 7.00$ & $p<0.05$ & $p<0.01$ & 0.07 \\
\hline CYP27B1_assay 1 & $10.20 \pm 12.19$ & $3.28 \pm 0.94$ & $7.88 \pm 7.06$ & 0.24 & 0.75 & 0.19 \\
\hline CYP27B1_assay 2 & $7.14 \pm 8.88$ & $0.50 \pm 0.31$ & $6.38 \pm 8.64$ & 0.13 & 0.90 & 0.17 \\
\hline CYP27B1_assay 4 & $43.56 \pm 2.13$ & $44.90 \pm 3.89$ & $45.90 \pm 5.26$ & 0.52 & 0.38 & 0.74 \\
\hline ENTPD5_assay 1 & $1.68 \pm 0.56$ & $1.74 \pm 0.11$ & $1.88 \pm 0.60$ & 0.80 & 0.62 & 0.62 \\
\hline FADS1_assay 1 & $12.76 \pm 17.16$ & $4.70 \pm 7.95$ & $2.94 \pm 5.80$ & 0.37 & 0.26 & 0.70 \\
\hline MAL_assay 1 & $11.76 \pm 10.80$ & $61.16 \pm 40.61$ & $84.68 \pm 11.92$ & $p<0.05$ & $p<0.01$ & 0.25 \\
\hline PRIMA1_assay 1 & $4.00 \pm 0.85$ & $32.56 \pm 31.71$ & $26.42 \pm 33.03$ & 0.08 & 0.17 & 0.77 \\
\hline PRIMA1_assay 2 & $2.34 \pm 1.13$ & $29.82 \pm 22.74$ & $29.45 \pm 35.82$ & $p<0.05$ & 0.13 & 0.99 \\
\hline PRIMA1_assay 3 & $21.70 \pm 25.92$ & $73.64 \pm 28.56$ & $93.55 \pm 3.06$ & $p<0.05$ & $p<0.01$ & 0.21 \\
\hline PRIMA1_assay 4 & $0.62 \pm 0.73$ & $43.61 \pm 29.53$ & $59.91 \pm 31.31$ & $p<0.05$ & $p<0.01$ & 0.42 \\
\hline PTGDR assay 1 & $2.95 \pm 0.80$ & $3.16 \pm 2.52$ & $28.94 \pm 10.72$ & 0.87 & $p<0.01$ & $p<0.01$ \\
\hline PTGDR assay 2 & $6.40 \pm 3.82$ & $3.56 \pm 1.26$ & $23.81 \pm 10.40$ & 0.15 & $p<0.01$ & $p<0.01$ \\
\hline PTGDR_assay 3 & $1.63 \pm 3.23$ & $1.14 \pm 1.45$ & $25.72 \pm 20.81$ & 0.77 & $p<0.05$ & $p<0.05$ \\
\hline PTGS2_assay 1 & $5.80 \pm 6.58$ & $2.33 \pm 0.33$ & $3.05 \pm 1.00$ & 0.27 & 0.44 & 0.17 \\
\hline PTGS2_assay 2 & $9.66 \pm 8.80$ & $0.83 \pm 0.80$ & $18.19 \pm 36.43$ & 0.06 & 0.62 & 0.32 \\
\hline SFRP1_assay 1 & $19.03 \pm 25.20$ & $78.72 \pm 23.36$ & $91.08 \pm 5.91$ & $p<0.01$ & $p<0.01$ & 0.28 \\
\hline SFRP2_assay 1 & $12.53 \pm 5.01$ & $55.95 \pm 31.32$ & $90.78 \pm 1.56$ & $p<0.05$ & $p<0.01$ & 0.06 \\
\hline SFRP2_assay 2 & $16.34 \pm 9.82$ & $68.90 \pm 27.80$ & $85.16 \pm 2.56$ & $p<0.01$ & $p<0.01$ & 0.29 \\
\hline SOCS3_assay 1 & $3.86 \pm 0.84$ & $6.57 \pm 5.39$ & $25.07 \pm 14.20$ & 0.30 & $p<0.05$ & $p<0.05$ \\
\hline sOCS3_assay 2 & $14.28 \pm 8.30$ & $68.61 \pm 35.98$ & $90.36 \pm 8.66$ & $p<0.05$ & $p<0.01$ & 0.28 \\
\hline sOCS3_assay 3 & $2.59 \pm 2.72$ & $55.24 \pm 43.52$ & $85.04 \pm 12.02$ & $p<0.05$ & $p<0.01$ & 0.23 \\
\hline SULF1_assay 1 & $4.62 \pm 4.06$ & $7.52 \pm 8.25$ & $16.12 \pm 17.25$ & 0.50 & 0.18 & 0.34 \\
\hline SULF1_assay 2 & $4.75 \pm 4.58$ & $8.35 \pm 12.00$ & $8.46 \pm 4.78$ & 0.59 & 0.31 & 0.99 \\
\hline SULT1A1_assay 1 & $2.54 \pm 1.05$ & $4.63 \pm 3.81$ & $4.02 \pm 2.15$ & 0.27 & 0.20 & 0.76 \\
\hline SULT1A1_assay 2 & $45.35 \pm 7.51$ & $38.07 \pm 4.36$ & $56.53 \pm 26.33$ & 0.10 & 0.39 & 0.16 \\
\hline SULT1A1_assay 3 & $13.90 \pm 16.07$ & $7.69 \pm 8.11$ & $7.87 \pm 12.23$ & 0.47 & 0.57 & 0.98 \\
\hline THBS2_assay 1 & $13.64 \pm 6.67$ & $45.55 \pm 25.89$ & $49.61 \pm 8.64$ & $p<0.05$ & $p<0.01$ & 0.75 \\
\hline THBS2_assay 2 & $90.83 \pm 2.02$ & $84.92 \pm 8.28$ & $83.33 \pm 10.87$ & 0.16 & 0.17 & 0.80 \\
\hline THBS2_assay 3 & $90.16 \pm 2.37$ & $87.54 \pm 3.22$ & $78.65 \pm 8.85$ & 0.18 & $p<0.05$ & 0.07 \\
\hline THBS2_assay 4 & $24.84 \pm 18.37$ & $42.88 \pm 8.47$ & $42.48 \pm 18.50$ & 0.11 & 0.33 & 0.97 \\
\hline TIMP1_assay 1 & $32.62 \pm 21.75$ & $15.35 \pm 20.90$ & $5.35 \pm 2.27$ & 0.24 & $p<0.05$ & 0.32 \\
\hline
\end{tabular}

COL1A2, FADS1, SFRP1, SULF1, and THBS2) showed unique gene expression alterations only in CRC samples. More specifically, looking at cellular components of the abovementioned stages of CRC formation, the results showed that epithelial cells in $\mathrm{AD}$ express decreased amounts of SOCS3 and PRIMA1, whereas those in CRC express less BCL2, CYP27B1, COL1A2, FADS1, and SULT1A1.

Demethylation treatment of colon adenocarcinoma cell lines led to varying degrees of upregulation of certain transcripts. In HT-29 cell line ALDH1A3 and SOCS3 was found to be upregulated by $0.5 \mu \mathrm{M} 5$-Aza.
Interestingly, in HCT-116 cells PTGS2; and in SW480 cell line TIMP1 showed higher expression after 0.5 and 3 MM 5-Aza treatments, as well.

From the resulting marker set, COL1A2, SFRP2, and SOCS3 were hypermethylated and THBS2 was hypomethylated in both $\mathrm{AD}$ and CRC samples compared to NAT. Based on the literature, hypermethylation of COL1A2 was confirmed in head and neck cancer [20], melanoma [21], and bladder cancer [22]. This is suggestive that COL1A2 may contribute to the formation of various cancers by modulating cell proliferation and migration. In the gastrointestinal tract, expression of COL1A2 

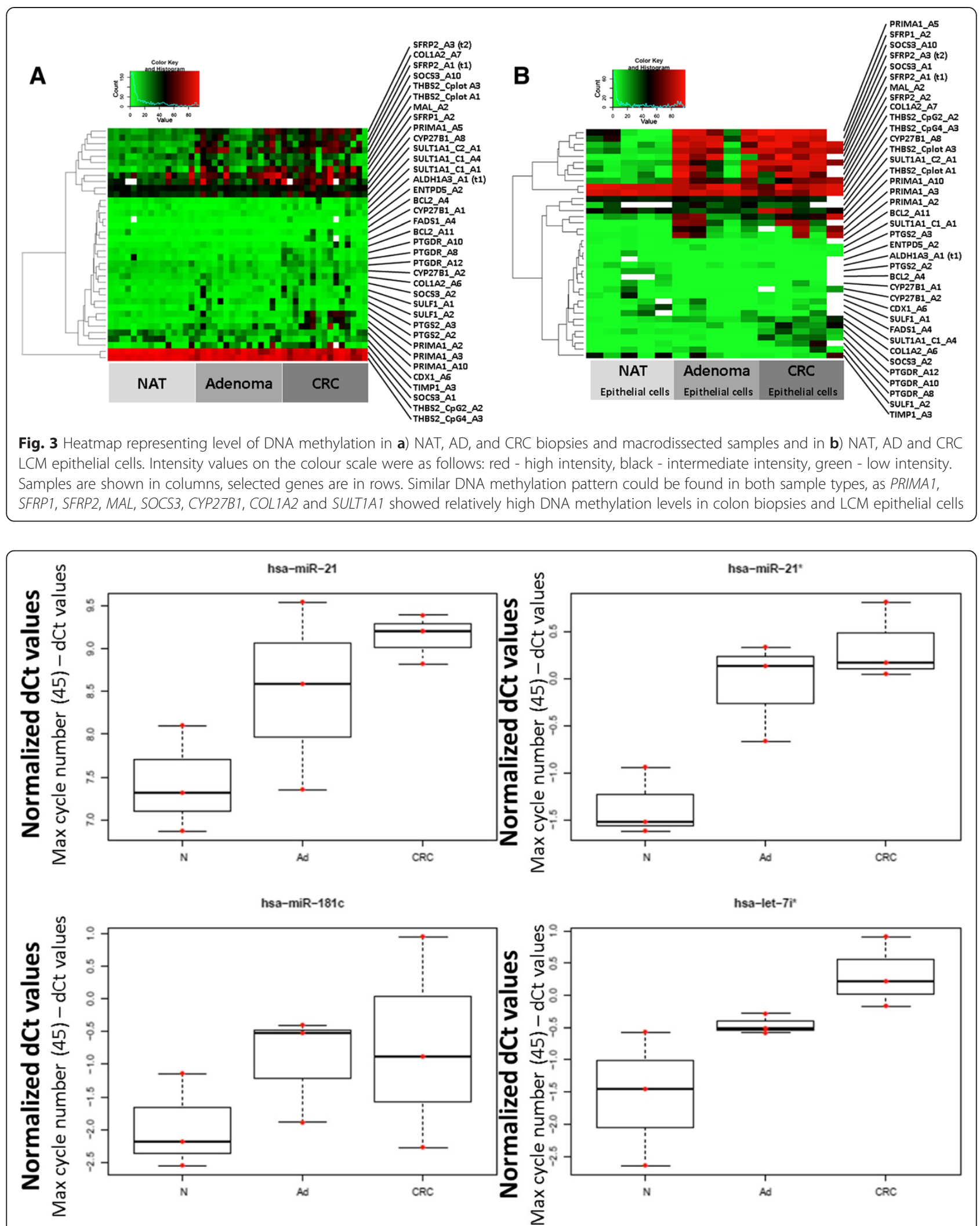

Fig. 4 Normalised Ct values of selected miRNAs (hsa-miR-21, hsa-miR-21*, hsa-miR-181c, hsa-let-7i*) targeting the selected marker set. Raw Ct data were substracted from the maximal qPCR cycle number (45) and data were normalised with interplate calibrators and also with miR-423-5p Ct values. Red dots represent individual miRNA normalised Ct values, box plots represent median and standard deviation of the data 


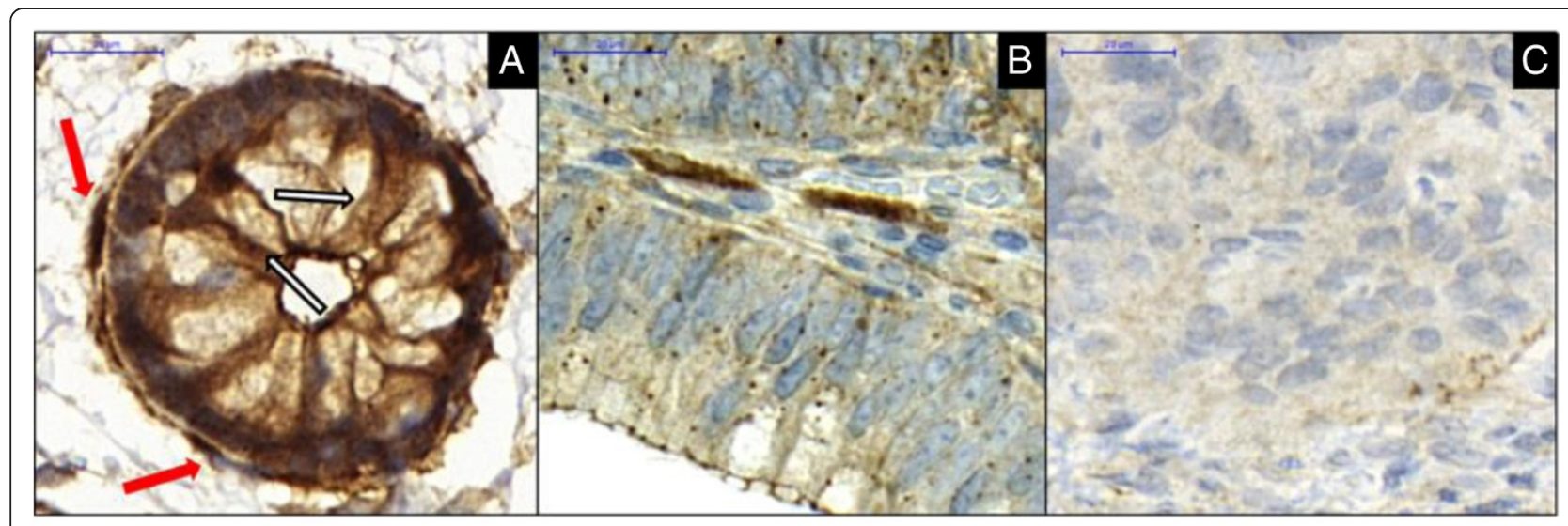

D SFRP1 immunohistochemistry (Q-score)

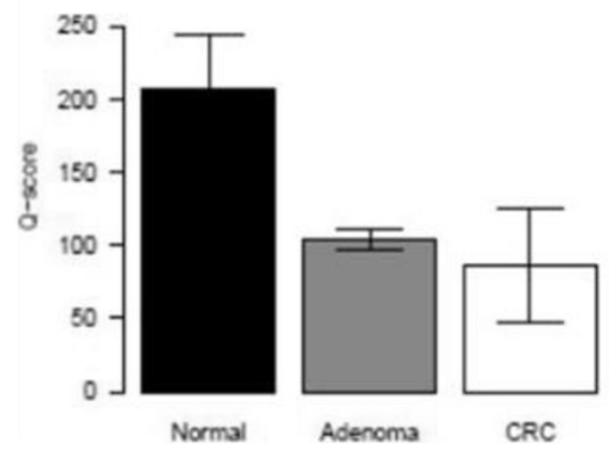

Fig. 5 Continuously decreasing SFRP1 protein expression could be observed along colorectal adenoma-carcinoma development in epithelial/CRC compartment of NAT (a), AD (b), and CRC (c) samples. SFRP1 protein expression of healthy epithelial cells (a, white arrows) was compared to that in endogenous myofibroblasts (a, red arrows) with strong (+3) immunopositivity (digital microscopy images, 90x magnification, scale bar: $20 \mu \mathrm{m}$ ). Semiquantitative immunohistochemistry results (Q-score values) of NAT, AD, and CRC specimens are summarised as bar charts with whiskers representing standard deviation $(\mathbf{d})$

may be associated with endothelial-to-mesenchymal transition [23]. Collagen production of carcinoma cells decreases during oncogenic transformation [24]; and, hypermethylation of COL1A2 was confirmed in several CRC cell lines (HCT 116, SW480, and SW620) as well as in primary CRC tissues [25]. SFRP2 is a member of the well-known inhibitors of Wnt pathway, abnormal activation of which (e.g. via $A P C$ mutation or beta-catenin translocation) is a frequent and early event in the genesis of CRC [26]. It has already been shown to be hypermethylated in colorectal cancer cell lines (e.g. HCT116) as well as primary CRC [27, 28]. Furthermore, it has recently been recognised as a promising and sensitive marker of stool-based screening of CRC [26]. SOCS3 is a negative regulator of the JAK-STAT3 pathway; therefore, it may effect cell proliferation and cell cycle [29]. Mutational analysis of the gene revealed no marked association between SOCS3 promoter region polymorphisms and the risk of developing metastatic colorectal cancer [30]. Epigenetic inactivation of SOCS3 was reported in human malignant melanomas and glioblastoma multiforme [31, 32]. Reduced gene expression of SOCS3 was found in the colitis ulcerosa (UC) to CRC progression from low-grade dysplasia to CRC. Related to this, DNA methylation of SOCS3 could also be detected in colonic biopsies of UC-CRC patients but not from healthy controls or from inactive UC patients [33, 34]. THBS2 hypermethylation might be responsible for altered expression of thrombospondin-2 protein in ovarian cancer and endometrial adenocarcinomas [35]. Thrombospondin-2 is an antiangiogenetic factor in $\mathrm{CRC}$ and its expression was associated with angiogenesis and metastasis formation inhibition in CRC [36].

The set of BCL2, PRIMA1, and PTGDR showed hypermethylation only in CRC. BCL2 (B-cell CLL/lymphoma 2) is an apoptotic inhibitor. Its hypermethylation was documented in breast cancer [37] and bladder cancer [38]. Bcl-2 protein plays a role in CRC formation [39] and has a reduced expression in CRCs with microsatellite instability [40]. DNA hypermethylation of BCL2 was detected in CRC cases; however, there was no relationship between gene expression and methylation of specific CpG sites [41]. PRIMA1 encodes a membrane protein anchoring acetylcholinesterase to cell membranes 
[42]. Its promoter hypermethylation was detected in major depressive disorder with a concomitant decrease in gene expression [43]. It has not yet been associated with CRC development. Decreased mRNA expression levels of PTGDR genes in colorectal AD and CRC caused by DNA methylation were previously described [8].

In summary MAL, PRIMA1, PTGDR and SFRP1 showed a downregulation of gene expression and in parallel increasing DNA methylation level that correlated with CRC development. Meanwhile, BCL2, CDX1, ENTPD5 and SULT1A1 dowregulation was not accompanied with significant DNA methylation changes; thus, other regulatory processes should be further investigated to understand these changes in gene expression.

After DNA methylation analysis of candidate genes with altered gene expression, the potential influence of DNA methylation on the protein level was also investigated. Significantly decreasing protein levels of SFRP1 could be observed along the adenoma-carcinoma sequence. This result is in accordance with the literature, as epigenetic regulation of SFRP1 can lead to decreased protein levels [44, 45].

On a limited sample set miRNAs with upregulation along the AD-CRC sequence were also identified. miR21 was found to be remarkably upregulated in $\mathrm{AD}$ and CRC samples compared to NAT controls. On the basis of in silico prediction miR-21 can target genes showing no remarkable alteration in their promoter methylation (e.g. BCL2, MAL, PTGS2) during CRC development, that might influence their gene expression levels. miR21 is known to play role in tumour formation and was also found to be upregulated in CRC tissues along tumour formation $[46,47]$. The expression level of miR21 is elevated both in colorectal adenomas and cancers, and the degree of upregulation correlates with more advanced stages of CRC [7]. This small non-coding RNA could have a fundamental role in the progression of CRC, as elevated level of miR-21 was found to be predictive of poor survival [48], that may increase proliferation, migration and invasion. In CRC cell lines with the EMT phenotype the expression of miR-21 oncomiR is regulated by AP-1 and ETS transciption factors and also by epigenetic factors. Activating histone modifications (H3K3me3, H3K914ac, H3K27ac), but no inactivating were detected on miR-21 promoter region [49]. These epigenetic mechanisms can affect the binding affinity of transcription factors to the miR-21 promoter regulating its expression level. Upregulated miR-181 in CRC cases might also influence gene expression level of the Bcl-2 family members [50].

\section{Conclusion}

In summary, we identified 18 transcripts with changes in gene expression that correlate with CRC development. On the basis of genome-wide gene expression-based screening we could identify genes potentially downregulated by promoter hypermethylation. Silencing of the markers identified in our study by hypermethylation or miRNA upregulation can result in reduced gene expression leading to decreased protein levels contributing to CRC formation.

\section{Additional files}

\section{Additional file 1: Table S1. Clinical data of the analysed gene expression datasets (GSE4183, GSE37364, GSE10714 and GSE15960). (DOC 249 kb)}

Additional file 2: Table S2. Clinical data of patients involved in the study. (DOCX $24 \mathrm{~kb}$ )

Additional file 3: Figure S1. Gene expression of the selected marker set in normal $(n=49)$, adenoma $(n=49)$, and tumour $(n=49)$ biopsy samples. Results are represented as pairwise box plots showing single gene expession in the biopsy and in the laser microdissected epithelial cells from normal $(n=6)$, adenoma $(n=6)$, and tumour $(n=6)$. Red dots are normalised gene expression values, box plots represent median and standard deviation of the data. Asterisk $\left(^{*}\right)$ represents significance $(p<0.05)$ in adenoma and tumour samples compared to normals and double asterisk $\left({ }^{*}\right)$ represents significance $(p<0.05)$ in tumour samples compared to adenomas. Each box plot has individual scale of gene expression. Changes in the direction of gene expression was found to be similar in colon biopsies and in LCM epithelial cells. (PDF 296 kb)

Additional file 4: Table S3. Summary of gene expression and DNA methylation data. (XLS 49 kb)

Additional file 5: Figure S2. Box plot representation of DNA methylation alterations of analysed genes in biopsies and macrodissected specimens of NAT $(n=10), \operatorname{AD}(n=10)$, and CRC $(n=10)$ and in LCM epithelial cells of NAT $(n=5), \operatorname{AD}(n=5)$ and CRC $(n=5)$. Red dots are individual DNA methylation percent values, box plots represent median and standard deviation of the data. Asterisk $(*)$ represents significance $(p<0.05)$ in adenoma and tumour samples compared to normals and double asterisk $\left({ }^{* *}\right)$ represents significance $(p<0.05)$ in tumour samples compared to adenomas. Each box plot has individual scale of DNA methylation percent. Certain genes showe hypermethylation in colon biopsies and also in LCM epithelial cells (e.g. MAL, PRIMA1, PTGDR, SFRP2), while there were genes with no remarkable DNA methylation level alterations (e.g. BCL2, CDX1, PTGS2, SULF1). Macro = macrodissected samples, LCM = laser microdissected epithelial cells. (PDF 359 kb)

\section{Abbreviations}

NAT: Normal tissue adjacent to tumour; AD: Adenoma; CRC: Colorectal cancer; LCM: Laser capture microdissection; CpG: CG dinucleotide; bcDNA: bisulfite-converted DNA; BS-PCR: Bisulfite-sequencing PCR; emPCR: emulsion-PCR; FFPE: Formalin-fixed and paraffin-embedded; TMA: Tissue microarray.

\section{Competing interests}

The authors declare that they have no competing interests.

\section{Authors' contributions}

$\mathrm{AK}, \mathrm{BP}, \mathrm{PH}$, and AVP performed the DNA methylation analysis; OG, SS, KT, and $\mathrm{KL}$ performed the microarray experiments; $\mathrm{BW}$ and $\mathrm{AB}$ conducted bioinformatical analyses; GV analysed immunhistochemistry results; NZS performed miRNA expression experiments, ZT, IK, BM contributed to the design and critical review of the manuscript. All authors read and approved the final manuscript.

\section{Acknowledgements}

This study was supported by the National Office for Research and Technology, Hungary (TECH_08-A1/2-2008-0114 and NFÜ-KMR 12-1-2012-0216 grants) and by the Hungarian Scientific Research Fund (OTKA-103244 and OTKA-K111743 
grants). The authors would like to thank Katalin Kiss, Zsolt Horváth, and Kornélia Baghy (1st Department of Pathology and Experimental Cancer Research, Semmelweis University) for performing laser capture microdissection and Gabriella Kónyáné Farkas ( $2^{\text {nd }}$ Department of Internal Medicine, Semmelweis University) for her technical assistance in immunohistochemical stainings. Authors gratefully thank Theo deVos for language revision of the manuscript.

\section{Author details}

²nd Department of Internal Medicine, Semmelweis University, Budapest, Hungary. ${ }^{2}$ Molecular Medicine Research Group, Hungarian Academy of Sciences, Budapest, Hungary. ${ }^{3} 1$ st Department of Pathology and Experimental Cancer Research, Semmelweis University, Budapest, Hungary. ${ }^{4}$ Tumour Progression Research Group, Hungarian Academy of Sciences, Budapest, Hungary. ${ }^{5}$ Department of Physics of Complex Systems, Eötvös Loránd University, Budapest, Hungary.

\section{Received: 13 October 2014 Accepted: 7 October 2015 Published online: 19 October 2015}

\section{References}

1. Ferlay J, Shin HR, Bray F, Forman D, Mathers C, Parkin DM. Estimates of worldwide burden of cancer in 2008: GLOBOCAN 2008. Int J Cancer Journal International du cancer. 2010;127(12):2893-917.

2. Colussi D, Brandi G, Bazzoli F, Ricciardiello L. Molecular pathways involved in colorectal cancer: implications for disease behavior and prevention. Int J Mol Sci. 2013;14(8):16365-85.

3. Pancione M, Remo A, Colantuoni V. Genetic and epigenetic events generate multiple pathways in colorectal cancer progression. Pathol Res Int. 2012;2012:509348.

4. Kim MS, Lee J, Sidransky D. DNA methylation markers in colorectal cancer. Cancer Metastasis Rev. 2010;29(1):181-206.

5. Baylin SB, Herman JG, Graff JR, Vertino PM, Issa JP. Alterations in DNA methylation: a fundamental aspect of neoplasia. Adv Cancer Res. 1998;72:141-96.

6. Sakai T, Toguchida J, Ohtani N, Yandell DW, Rapaport JM, Dryja TP. Allele-specific hypermethylation of the retinoblastoma tumor-suppressor gene. Am J Hum Genet. 1991:48(5):880-8.

7. Schetter AJ, Okayama H, Harris CC. The role of microRNAs in colorectal cancer. Cancer J. 2012;18(3):244-52.

8. Spisak S, Kalmar A, Galamb O, Wichmann B, Sipos F, Peterfia B, et al. Genome-wide screening of genes regulated by DNA methylation in colon cancer development. PLoS One. 2012;7(10):e46215.

9. Galamb O, Wichmann B, Sipos F, Spisak S, Krenacs T, Toth K, et al. Dysplasia-carcinoma transition specific transcripts in colonic biopsy samples. PLoS One. 2012;7(11):e48547.

10. Galamb O, Gyorffy B, Sipos F, Spisak S, Nemeth AM, Miheller P, et al. 2008 Inflammation, adenoma and cancer: objective classification of colon biopsy specimens with gene expression signature. Dis Markers. 25(1): p. 1-16.

11. Galamb O, Sipos F, Solymosi N, Spisak S, Krenacs T, Toth K, et al. 2008 Diagnostic mRNA expression patterns of inflamed, benign, and malignant colorectal biopsy specimen and their correlation with peripheral blood results. Cancer Epidemiol Biomarkers Prev. 17(10):2835-45.

12. Rice P, Longden I, Bleasby A. EMBOSS: the European Molecular Biology Open Software Suite. Trends Genet. 2000;16(6):276-7.

13. Tusnady GE, Simon I, Varadi A, Aranyi T. BiSearch: primer-design and search tool for PCR on bisulfite-treated genomes. Nucleic Acids Res. 2005:33(1):e9.

14. Tost J, El abdalaoui H, Gut IG. Serial pyrosequencing for quantitative DNA methylation analysis. BioTechniques. 2006;40(6):721. -722, 724, 726.

15. Tost J, Gut IG. DNA methylation analysis by pyrosequencing. Nat Protoc. 2007;2(9):2265-75

16. Smith TF, Waterman MS. Identification of common molecular subsequences. J Mol Biol. 1981;147(1):195-7.

17. Gotoh O. An improved algorithm for matching biological sequences. J Mol Biol. 1982;162(3):705-8.

18. Luo C, Tsementzi D, Kyrpides N, Read T, Konstantinidis KT. Direct comparisons of Illumina vs. Roche 454 sequencing technologies on the same microbial community DNA sample. PLoS One. 2012;7(2):e30087.

19. Dweep H, Sticht C, Pandey P, Gretz N. miRWalk-database: prediction of possible miRNA binding sites by "walking" the genes of three genomes. J Biomed Inform. 2011;44(5):839-47.
20. Misawa K, Kanazawa T, Misawa Y, Imai A, Endo S, Hakamada K, et al. Hypermethylation of collagen alpha2 (I) gene (COL1A2) is an independent predictor of survival in head and neck cancer. Cancer Biomark. 2011;10(3-4):135-44.

21 Bonazzi VF, Nancarrow DJ, Stark MS, Moser RJ, Boyle GM, Aoude LG, et al. Cross-platform array screening identifies COL1A2, THBS1, TNFRSF10D and UCHL1 as genes frequently silenced by methylation in melanoma. PLoS One. 2011:6(10):e26121.

22. Mori K, Enokida H, Kagara I, Kawakami K, Chiyomaru T, Tatarano S, et al. CpG hypermethylation of collagen type I alpha 2 contributes to proliferation and migration activity of human bladder cancer. Int J Oncol. 2009;34(6):1593-602.

23. Sadler T, Scarpa M, Rieder F, West G, Stylianou E. Cytokine-induced chromatin modifications of the type I collagen alpha 2 gene during intestinal endothelial-to-mesenchymal transition. Inflamm Bowel Dis. 2013;19(7):1354-64.

24. Dahlman T, Lammerts E, Bergstrom D, Franzen A, Westermark K, Heldin NE, et al. Collagen type I expression in experimental anaplastic thyroid carcinoma: regulation and relevance for tumorigenicity. Int J Cancer Journal International du cancer. 2002;98(2):186-92.

25. Sengupta PK, Smith EM, Kim K, Murnane MJ, Smith BD. DNA hypermethylation near the transcription start site of collagen alpha2(I) gene occurs in both cancer cell lines and primary colorectal cancers. Cancer Res. 2003;63(8):1789-97.

26. Cancer Genome Atlas N. Comprehensive molecular characterization of human colon and rectal cancer. Nature. 2012;487(7407):330-7.

27. Suzuki H, Watkins DN, Jair KW, Schuebel KE, Markowitz SD, Chen WD, et al. Epigenetic inactivation of SFRP genes allows constitutive WNT signaling in colorectal cancer. Nat Genet. 2004;36(4):417-22.

28. Wang DR, Tang D. Hypermethylated SFRP2 gene in fecal DNA is a high potential biomarker for colorectal cancer noninvasive screening. World J Gastroenterol. 2008;14(4):524-31.

29. Wei X, Wang G, Li W, Hu X, Huang Q, Xu K, et al. Activation of the JAK-STAT3 pathway is associated with the growth of colorectal carcinoma cells. Oncol Rep. 2014;31(1):335-41.

30. Igci M, Cakmak EA, Oztuzcu S, Bayram A, Arslan A, Gogebakan B, et al. Mutational screening of the SOCS3 gene promoter in metastatic colorectal cancer patients. Genet Test Mol Biomarkers. 2012;16(12):1395-400.

31. Tokita T, Maesawa C, Kimura T, Kotani K, Takahashi K, Akasaka T, et al. Methylation status of the SOCS3 gene in human malignant melanomas. Int J Oncol. 2007;30(3):689-94

32. Feng Y, Wang Z, Bao Z, Yan W, You G, Wang Y, et al. SOCS3 Promoter Hypermethylation Is a Favorable Prognosticator and a Novel Indicator for G-CIMP-Positive GBM Patients. PLoS One. 2014;9(3):e91829.

33. Li Y, de Haar C, Chen M, Deuring J, Gerrits MM, Smits R, et al. Disease-related expression of the IL6/STAT3/SOCS3 signalling pathway in ulcerative colitis and ulcerative colitis-related carcinogenesis. Gut. 2010;59(2):227-35.

34. Li Y, Deuring J, Peppelenbosch MP, Kuipers EJ, de Haar C, van der Woude CJ. IL-6-induced DNMT1 activity mediates SOCS3 promoter hypermethylation in ulcerative colitis-related colorectal cancer. Carcinogenesis. 2012;33(10):1889-96.

35. Whitcomb BP, Mutch DG, Herzog TJ, Rader JS, Gibb RK, Goodfellow PJ. Frequent HOXA11 and THBS2 promoter methylation, and a methylator phenotype in endometrial adenocarcinoma. Clin Cancer Res. 2003;9(6):2277-87.

36. Tokunaga T, Nakamura M, Oshika Y, Abe Y, Ozeki Y, Fukushima Y, et al. Thrombospondin 2 expression is correlated with inhibition of angiogenesis and metastasis of colon cancer. Br J Cancer. 1999;79(2):354-9.

37. Stone A, Cowley MJ, Valdes-Mora F, McCloy RA, Sergio CM, Gallego-Ortega $\mathrm{D}$, et al. BCL-2 hypermethylation is a potential biomarker of sensitivity to antimitotic chemotherapy in endocrine-resistant breast cancer. Mol Cancer Ther. 2013;12(9):1874-85.

38. Friedrich MG, Weisenberger DJ, Cheng JC, Chandrasoma S, Siegmund KD, Gonzalgo ML, et al. Detection of methylated apoptosis-associated genes in urine sediments of bladder cancer patients. Clin Cancer Res. 2004;10(22):7457-65.

39. Torsello A, Garufi C, Cosimelli M, Diodoro MG, Zeuli M, Vanni B, et al. P53 and bcl-2 in colorectal cancer arising in patients under 40 years of age: distribution and prognostic relevance. Eur J Cancer. 2008;44(9):1217-22.

40. Biden KG, Simms LA, Cummings M, Buttenshaw R, Schoch E, Searle J, et al. Expression of $\mathrm{BCl}-2$ protein is decreased in colorectal adenocarcinomas with microsatellite instability. Oncogene. 1999;18(5):1245-9. 
41. Babidge WJ, Butler LM, Burton MA, Cowled PA. Methylation of CpG sites in exon 2 of the bcl-2 gene occurs in colorectal carcinoma. Anticancer Res. 2001;21(4A):2809-14.

42. Xie HQ, Liang D, Leung KW, Chen VP, Zhu KY, Chan WK, et al. Targeting acetylcholinesterase to membrane rafts: a function mediated by the proline-rich membrane anchor (PRiMA) in neurons. J Biol Chem. 2010;285(15):11537-46

43. Sabunciyan S, Aryee MJ, Irizarry RA, Rongione M, Webster MJ, Kaufman WE, et al. Genome-wide DNA methylation scan in major depressive disorder. PLoS One. 2012;7(4):e34451.

44. Dahl E, Wiesmann F, Woenckhaus M, Stoehr R, Wild PJ, Veeck J, et al. Frequent loss of SFRP1 expression in multiple human solid tumours: association with aberrant promoter methylation in renal cell carcinoma. Oncogene. 2007;26(38):5680-91

45. Valcz G, Patai AV, Kalmar A, Peterfia B, Furi I, Wichmann B, et al. Myofibroblast-derived SFRP1 as potential inhibitor of colorectal carcinoma field effect. PLoS One. 2014;9(11):e106143.

46. Slaby O, Svoboda M, Fabian P, Smerdova T, Knoflickova D, Bednarikova M, et al. Altered expression of miR-21, miR-31, miR-143 and miR-145 is related to clinicopathologic features of colorectal cancer. Oncology. 2007;72(5-6):397-402.

47. Si ML, Zhu S, Wu H, Lu Z, Wu F, Mo YY. miR-21-mediated tumor growth. Oncogene. 2007;26(19):2799-803.

48. Xia X, Yang B, Zhai X, Liu X, Shen K, Wu Z, et al. Prognostic role of microRNA-21 in colorectal cancer: a meta-analysis. PLoS One. 2013;8(11):e80426.

49. Ferraro A, Kontos CK Boni T, Bantounas I, Siakouli D, Kosmidou V et al. Epigenetic regulation of miR-21 in colorectal cancer: ITGB4 as a novel miR-21 target and a three-gene network (miR-21-ITGBeta4-PDCD4) as predictor of metastatic tumor potential. Epigenetics. 2014;9(1):129-41.

50. Ouyang YB, Lu Y, Yue S, Giffard RG. miR-181 targets multiple Bcl-2 family members and influences apoptosis and mitochondrial function in astrocytes. Mitochondrion. 2012;12(2):213-9.

\section{Submit your next manuscript to BioMed Central and take full advantage of:}

- Convenient online submission

- Thorough peer review

- No space constraints or color figure charges

- Immediate publication on acceptance

- Inclusion in PubMed, CAS, Scopus and Google Scholar

- Research which is freely available for redistribution 